\title{
INEBRIETY AND FEEBLE- MINDEDNESS.
}

\author{
BY JAMES P. STURROCK, M.A., M.D., \\ Medical Officer, H.M. Prison, State Inebriate Reformatory, and Criminal \\ Lunatic Asylum, Perth.
}

THE common statement that inebriety is more often a symptom of mental defect than a cause of it has, I think, derived most of its apparent authority from its frequent repetition. It would seem almost as if we were in danger of forgetting that alcohol produces certain immediate and prolonged effects upon individual conduct, and that these are due to mental changes. The imbecile and those whom hitherto we have generally accepted as weakminded are probably not more addicted to alcohol than the more normal population. There is, however, no doubt that where there is existing mental defect the changes produced by alcohol are apt to be intensified, but whether that is always in the direction of antisocial conduct is a point that is not definite. Indeed, even in this class we must take into account another factor that is often lost sight of in the criminal inebriate-viz., the disposition of the individual. One can scarcely believe that the drunkard who beats his wife is either much attached to her when he is sober or is normally in a constant state of wishing to beat her from which his self-control deters him.

Inebriety is not confined to the criminal classes, but the definition of an inebriate has so widened the circle of abnormal conduct that shall come under the cognizance of the law that we must more than ever keep in view these two factors of disposition and the individual mental effects of alcohol. These effects are well exemplified in two classes of inebriates who are continually increasing, and who constitute, perhaps, the larger proportion of those who have hitherto been dealt with under the Inebriates 
Act. These cases of habitual drunkenness and cruelty to, or, strictly speaking, neglect of, family are really crimes of omission. Much of the debate as to mental defect has centred around these. The habitual "drunk and disorderly" constitute the large proportion of the prison "ins and outs," whose treatment there has been so hopelessly unsuccessful. That they are inebriates no one will deny; that they are all weak-minded is quite another question. Amongst this class there is a large proportion who show a marked intolerance to alcohol. This has been taken by some as evidence of mental defect, and has even been made a definition of inebriety. This intolerance is surely well marked in many persons who are neither inebriates nor criminals, and who are far from being weak-minded. Besides, if it were of the nature of actual mental defect it would be reasonable to expect that after years of this conduct most of these habituals would become distinctly defective or insane. Some may, but there are many amongst the older habituals here who show so little mental defect that they cannot differ much in this respect from what they were when they began their disorderly career many years ago.

Much stress has been laid upon the statement that these prisoners show similar explosive tendencies in prison apart altogether from alcohol. Such is not my experience, and there are at least as many "explosives" amongst prisoners who do not drink. It will be found, I think, that these outbursts have chiefly taken place during reformatory sentences for reasons which are apart from ordinary mental defect. It is not to be wondered at if a person whose only offence is what is termed a " simple drunk" should in time show an irritable disposition towards authority when she finds herself confined for a period that seems out of proportion to the gravity of her offence, particularly if her disposition and desires are those of the city habitual. Such explosive cases form the greater proportion of the failures of the earlier attempts at reformatory treatment.

It may be presumed that everyone who is unable to stop drinking is defective in self-control. If a drinker is not conscious that he is any the worse for alcohol, his self-control need not be said to be affected at all. The habitual inebriate, then, who becomes excited after a small quantity of alcohol, though easy to classify as weak-minded in that his brain cannot carry much alcohol a most pernicious definition of weak-mindedness-is a very difficult person to treat. Many such cases have passed 
through the reformatory, causing discontent and disorder throughout their sentence. Many of them were put on conditional licence before their sentence expired, and behaved well while they had the fear over them of being returned to complete their sentence if they took drink. When this was removed, they reverted to their former habits, back to the freedom of a city after three years' deprivation of liberty and the irritation of a discipline which, though always kind, prevented them from doing as they pleased. The reformatory treatment that has been given these cases has been just what they will have if they are sent to an institution from the point of view of mental defect. Indeed, from my experience, the alcoholic who has been sent to an asylum, not to recover from alcoholic insanity, but for preventive measures-the explosive type-is much more unmanageable there.

Detention for this large class of inebriates must be on the understanding that according to the amount of freedom of action and approximation to conditions of liberty will be the success in regard to conduct and possible cure.

A closed building is useless. A complete labour colony is necessary, that will provide variety of work and abundant scope for well-conducted inmates. The term of detention should be indeterminate, and the process of education must be one of advancement and deprivation of privileges, with numerous houses for separating various temperaments, and, if necessary, provision for temporary treatment of refractory inmates. If we cannot prevent their getting alcohol, we must approach as nearly as possible to this condition from the other side if we are to call our method treatment and not punishment. We must put them in such a position that they have practically the freedom they formerly had without the means of obtaining alcohol, and with supervision and inducements to help them to control their dispositions in other harmful directions.

There is, in spite of much argument to the contrary, a great amount of mental defect resulting in inebriety that is secondary to ordinary prolonged drinking. The abolition of self-restraint which characterizes the early stages of alcoholism is manifested still more as the disease progresses and becomes inebriety. Apart from cases showing an underlying criminal disposition, we see this progressive diminution in the power of purposive direction best in the well-to-do inebriate, who becomes irregular in habits, 
untidy and even filthy in dress, dull in mind, and neglectful of family cares and social duties.

Some such moral failure characterizes the cases of neglect or of cruelty to children. There is little doubt that these have been drinking for longer periods than they say. Their condition on admission is often one of obvious mental defect, but it usually shows itself to be a secondary condition by improving, which no primary or congenital defect does in the same time, or probably at all, at the formed age at which these women are received. Attention is often directed chiefly to their inability to cease drinking as being evidence of defective self-control, whereas it is in the actual results produced by their drinking upon character and habits that defective self-control is evidenced. These women have been moderate but steady drinkers for years in most cases before they became degraded inebriates, and in many the early drinking was associated with explosive outbursts which they no longer exhibit. Many of them can keep from drinking for months at a time, especially after a sentence, and very often it is no desire of their own, but some accidental presentation of temptation that induces another bout. These cases require reformatory treatment to eradicate, if possible, the moral disability that is secondary to alcohol, and to remove any physical ailments that may be associated as a cause of the inebriety. There is thus a difficulty in fixing a period for reformatory treatment. Reformatory treatment can never be a question of how long it takes to get the alcohol out of the system-a loose phrase which has no physiological significance, and confuses alcohol either with its effects or with the craving, if there is such a definite state of mind. The real question is, What is the nature of the physical, mental, and moral dissolution of a particular inmate, and how long will it take to repair this sufficiently so that the inmate may go out with a reasonable hope of doing well ?

For the proper place to train a person to do without alcohol is outside the reformatory. Self-control in relation to any vice will be best strengthened and guided where it has to be exercised. Conditional liberation may be tried very soon in some cases, and though such a method of differentiation does cause jealousies, the ultimate results will doubtless be good.

The after-care is probably the most important factor in the treatment of the inebriate. Too much caution cannot be expended in deciding to how much of the former home surround- 


\section{The British Journal of Inebriety}

ings and occupations he may return. Periods of probation, both before consignment to a reformatory and after a stay there, are most promising methods. As the secondary mental defects should have entirely passed off before discharge, once he enters the reformatory he should be detained for five years if necessary, or more, instead of a statutory limit, and his probation should also be indefinite. At the first relapse then, or at any rate when he seems likely to start on a period of drinking, he can then be safely sent, not to the reformatory, but to the labour colony. 